\title{
The Study of How to Make Up the Culture Differences Between the Chinese and Western in Interpretation
}

\author{
Chengmei Dong, Hong Wang \\ Huanghai University of Qingdao, Shandong Province, China \\ 13708964336@163.com,wh201209@163.com
}

Key Words: cultural background ; cultural difference; interpreting; oral idioms vocabulary

\begin{abstract}
In the process of interpreting, Chinese and western cultural differences will affect our communication. This paper aims to explain that in cross-cultural communication, especially in the process of interpreting, as a translator, we should not only have excellent bilingual skills, but cultural background knowledge for both sides to be knowledgeable. Only by this way can we make up the culture difference between the Chinese and Western when we do the work of interpreting.
\end{abstract}

\section{Introduction}

As we all know, culture is a kind of superstructure. It is based on certain economic base, and closely connected with a country and the national tradition. "Cross-cultural communication", however, refers to communication between native speakers and the non-native speakers, also refers to any communication among people with differences in language and culture background. Due to the different nations of ecological, physical, social and religious environment, etc. Their language environment leads to various contextual factors for each different language habits, social culture, the local conditions and customs and so on. They express their thoughts and feeling by the cultural pattern which in accordance with their respective compliance, while lack understanding of both sides' respective cultural background. In many cases, therefore, communication failure or blocked is due to ignoring to convey the cultural connotation of bearing the language. Translation is a cross-cultural bridge, the tie of communication among different cultures. As an English interpreter, when we interpret something, we should try to strengthen the intelligibility of different cultures in the listeners' hearts and shorten the distance between the two kinds of languages and culture, even to eliminate the barrier due to lack of cultural understanding or even misunderstanding. In a word, we should really try our best to make interpretation as a kind of cultural transmission medium.

\section{2. the Differences of the Thinking Mode}

During the bilingual cultural communication, we should not only master the pronunciation, grammar, vocabulary and idioms, but also know people who use this language how to look at things and how to observe the world; To understand how they use their language to reflect their social thoughts, habits, behavior; To understand their "language of the soul", namely to understand their social culture. As a matter of fact, we can say it is a language communication rather than thought exchange. The process also reflects the thinking process of exchanging between both sides. This requires that interpreters, in addition to the solid fundamental language skills, not only have fluent language skills but also have the ability to understand its background and way of thinking. The thinking differences between Chinese and western people mainly displays in:

2.1 Chinese people pay more attention to "parataxis", while western "hypotaxis". The so-called "parataxis" refers to a sentence mainly linked by the meaning of the words together. And "hypotaxis" refers to the strong logical relations among language symbols. This shows as follow: Chinese sentences are simple and lively, with the aid of verbs, in chronological order and logical order step by step. The English sentence structures are compact closely. Special emphasis on dependency and modification among the components. Usually using conjunctions, prepositions, relative pronouns connect sentences, therefore, when conducting the interpreting activities we should pay attention to the characteristics of the two languages, according to the need to choose or 
make appropriate adaptations.

2.2 Chinese people pay attention to comprehensive thinking, while British and American people lay emphasis on the analytic thinking. Chinese people pay attention to the overall priority and links among things on thinking. British and American people always focus on partial priority, specific things and stressing on the reason analysis. This can be specific to the expression of space and time order. For example: when they write the address, the Chinese people always write with ascending order, which are quite different from Anglo-American countries, who often from the number of house then the district, the town, the city. When filling in the resume, the Chinese people fill their address from general to detail, while British and American people from detail to general. When stating opinions and discussing problems, they also reflect differences in two kinds of thinking. In China, we explain the reasons and then come to the point, but British and American people are straightforward questions.

\section{Some Sayings With No Corresponding Word in English and Chinese}

There is a proverb in Chinese; "xia lian san fu, dong lian san jiu" (Do physical exercise in dog days and keep on in winter.) to motivate people to build up their body. How to interpret the "san-fu" and the "san-jiu" in English? If you interpret them into "san-fu" and "san-jiu" or "three fu" and "three jiu", people in western country, of course, will be confused. We can interpret it into "In summer do physical exercise in dog days; in winter do the same thing during the coldest weather". Similarly, no corresponding expression in Chinese with "cowboy" and "hippie (or hippy)". The two words are the special products of American society. Cowboy is associated with the early development of the western region, in Chinese translating as "mu tong" or "niu zai", we can not reflect the real meaning. The hippie in Chinese, transliterating as "xi bi shi" or "xi bi pai", can not reflect the eccentric characteristics of American youth in the 60s, so transliterating as "xi pi shi " may be a little better.

\section{The Same Concepts: Different Implication}

Some concepts exist both in English and Chinese culture, but they are not fully synonymous. For example, the implications of "zhi shi fen zi" in Chinese and "intellectual" in the United States is very different in their respective cultural background.

In China, the "zhi shi fen zi "generally includes all the people received college education, such as college teachers, college students, doctors, engineers, interpreters, etc and secondary school teachers. In many rural places of China, even middle school students are also considered as "zhi shi fen zi". But in the United States and Europe, intellectual only include people with higher academic status, such as university professors, not including ordinary college students, so the word "intellectual" has a much smaller range. In addition, there are some other differences. The word "Intellectual" in the United States is not always positive, sometimes used in derogatory sense, which is similar as "chou lao jiu" in the cultural revolution in China. This example showed us not to consider annotations in the bilingual dictionary as completely corresponding synonyms, and also not to try finding corresponding word in different language to express the same thing. In addition, when some Chinese who know a little English introduce their partners with the word "lover", foreigners are quite surprised, (because the lover means mistress in English speaking country). Foreigners don't understand why Chinese people are always careful on this kind of matter but publicly to declare to have a lover? Keep in mind that the equivalent of the word "ai ren" in Chinese refers to husband (zhang fu) or wife (qi zi); fiance (wei hun fu) or fiancee (wei hun qi) in English language.

\section{Consistent with the original meaning of idioms, phrases and proverbs in interpreting}

Idiom translation problems are always very complex, if the historical and cultural background of the two languages are far more from each other, even more so. When compiling the Chinese-English dictionary (CED), compilers are with deep feelings to this. Many people think that this Dictionary is by far the best of its kind. Professor Zuoliang Wang, one of the Editors, in the book The Afterword of A Dictionary wrote: "The task of the translator is to understand the original meaning of the text first." If the interpreter don't understand the original text, of course, they can not find the equivalent words. The $20^{\text {th }}$ century Chinese writer Yutang Lin translated "chi ruan bu chi ying" to "bully the weak but 
yield to one who fights back", The interpretation is not only obscure in English, but shows that he didn't understand the true meaning of the phrase..... Only after a correct understanding of the original text can we see whether he, the interpreter has abundant foreign language level, and whether understands the development and changes in today's English speaking countries.

\section{Metaphor and Association}

There are a lot of metaphors in both English and Chinese, but because of the difference among social customs, cultural traditions, religious beliefs and aesthetic idea, the metaphor used in the two languages is also quite different. For example: ("You chicken!" He cried looking at Tom with contempt.) (not "You" this chicken.) People often associate certain qualities or characteristics with certain corresponding animals or objects.

These qualities or characteristics, often can make the person produce a reaction or an emotion, although the association has a little or no scientific basis. Associated features and caused emotions often also vary from different ethnic people. These metaphors in different cultural environment arouse people the same or different associations. For example: (He is as sly as a fox. He's foxy. You've got to watch him.) Chinese people have the same association of the above animals with American, British and Canadians. In fact, there also have the same saying like "stupid ass", "parrot like", "cunning as home fox", etc in Chinese. In the both cultures, similar associations with other animals are: Deer are timid and docile animal; A lamb is delightful and greedy; Pigs are dirty; The monkey is naughty. Then talk about association in the different situations. It can be divided into two classes: first, in a culture when people mentioned some animals they often can associate to certain characteristics, while in another culture no characteristics of it. Second, people will think some animals in two cultures of some characteristic but the associative characters are different.

\section{Summary}

Therefore, we can see that there are large influence on our interpretation activities from the culture differences. If we say that the lack of the understanding of the two languages respective cultural background can make the communication failed or blocked, then we can say translation is a cross-cultural bridge, also is the tie of communication existed in different culture. The translators or interpreters should try their best to strengthen the understandability of different cultures in the listeners' hearts and try to shorten the distance between the two kinds of languages and cultures. At the same time, the translators or interpreters should eliminate the disorder caused by lack of understanding or even misunderstanding of the two language cultures and really make interpretation as a kind of cultural transmission medium.

\section{Acknowledgement}

This paper is written on the base of the 2017 Research Subject of Education and Teaching of Young Teachers in Shandong Province - "the Motivation Research of College English Learning Under the Perspective of Cultural Identity".

\section{References}

[1] Shude Ding. Studies in Translation Techniques . Tianjin: Tianjin University Press, 2005.

[2] Zhongying Fan, An Applied Theory of Translation. Foreign Language Teaching and Research Press, 2000.

[3] Siqing Liu. English Varieties and Translation. Beijing: China Translation and Publishing Corporation, 1998.

[4] Edward C.Steward. "American Culture Patterns” [M]. Intercultural Press Inc. 1985. 